\title{
Hydrogen-Bonded Monolayers and Interdigitated Multilayers at the Air-Water Interface
}

Stephen M. Martin, ${ }^{\dagger}$ Kristian Kjaer, ${ }^{\ddagger}$, Markus J. Weygand, ${ }^{\ddagger, b}$ Isabelle Weissbuch, $*{ }^{\S}$ and Michael D. Ward $^{*} \dot{\psi}, c$

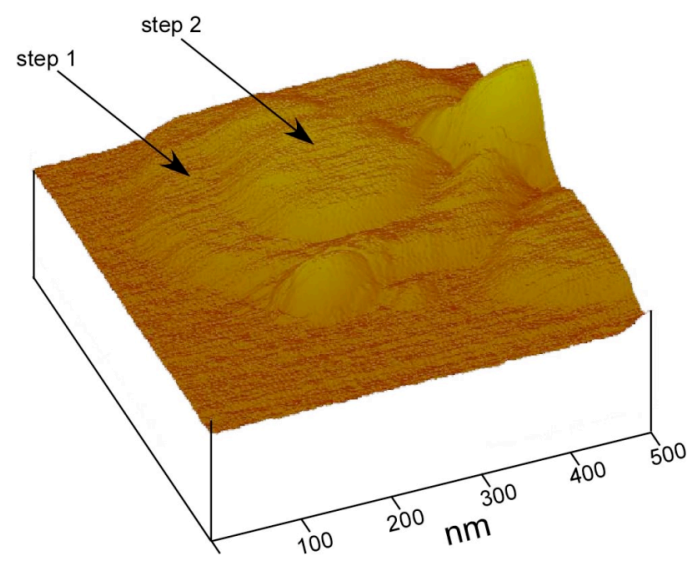

Figure S1. Tapping-mode atomic force microscope image of a $(\mathbf{G}) \mathrm{C} 18 \mathrm{~S}$ film transferred, via the LangmuirBlodgett technique, onto a mica substrate at $A_{m o l}=25 \AA^{2}$ /sulfonate. The height of the steps is ca. $30 \AA$. 